\title{
Hygrometric Properties of Inspired Gas and Oral Dryness in Patients With Acute Respiratory Failure During Noninvasive Ventilation
}

\author{
Jun Oto MD PhD, Emiko Nakataki MD PhD, Nao Okuda MD, Mutsuo Onodera MD, \\ Hideaki Imanaka MD PhD, and Masaji Nishimura MD PhD
}

\begin{abstract}
BACKGROUND: Because noninvasive ventilation (NIV) delivers medical gas at high flow, inadequate humidification may cause oral dryness and patient discomfort. Heated humidification can be used during NIV, but little has been reported about the effects on the hygrometric conditions inside an oronasal mask and oral dryness during 24 hours on NIV. METHODS: We measured absolute humidity $(\mathrm{AH})$ inside oronasal masks on subjects with acute respiratory failure during 24 hours on NIV. A single-limb turbine ventilator and oronasal mask with an exhalation port were used for NIV. Oral moistness was evaluated using an oral moisture-checking device, and 3 times during the 24 hours the subjects subjectively scored the feeling of dryness on a 0-10 scale in which 10 was the most severe dryness. RESULTS: Sixteen subjects were enrolled. The mean \pm SD AH inside the mask was $30.0 \pm 2.6 \mathrm{mg} \mathrm{H}_{2} \mathrm{O} / \mathrm{L}$ (range 23.1-33.3 $\mathrm{mg} \mathrm{H}_{2} \mathrm{O} / \mathrm{L}$ ). The median oral moistness was $19.2 \%$ (IQR 4.4-24.0\%), and the median oral dryness score was 5.5 (IQR 4-7). AH and inspired gas leak correlated inversely, both within the subjects $(r=-0.56, P<.001)$ and between the subjects $(\mathrm{r}=-0.58, P=.02)$. AH and oral moistness correlated within the subjects $(\mathrm{r}=0.39, P=.04)$. Oral breathing was associated with reduced oral moistness $(P=.001)$ and increased oral dryness score $(P=.002)$. CONCLUSIONS: AH varied among the subjects, and some complained of oral dryness even with heated humidifier. Oral breathing decreased oral moistness and worsened the feeling of dryness. Key words: noninvasive ventilation; heated humidifier; absolute humidity; oral dryness; acute respiratory failure. [Respir Care 2014;59(1):39-45. () 2014 Daedalus Enterprises]
\end{abstract}

\section{Introduction}

Widely used for patients with acute and chronic respiratory failure, noninvasive ventilation (NIV) delivers ventilatory support via oronasal mask, nasal mask, or nasal plugs. ${ }^{1}$ Especially when the NIV ventilator uses unhumidified gas, the upper airway can suffer mucosal dryness and airway dysfunction. The leak compensation applied by

\footnotetext{
The authors are affiliated with the Department of Emergency and Critical Care Medicine, University of Tokushima Graduate School, Tokushima, Japan.

The authors have disclosed no conflicts of interest.

Correspondence: Jun Oto MD PhD, Department of Emergency and Critical Care Medicine, University of Tokushima Graduate School, 3-18-15 Kuramoto-cho, Tokushima 770-8503, Japan. E-mail address: joto@clin.med.tokushima-u.ac.jp.
}

DOI: $10.4187 /$ respcare.02351
NIV ventilators creates high flow throughout the respiratory cycle, which contributes to loss of heat and moisture. ${ }^{2}$ About $40-60 \%$ of nasal CPAP users with obstructive sleep apnea report nasal congestion, oral dryness, and throat soreness after breathing dry, cold gases. ${ }^{3,4}$ Lack of humidification during NIV is related to greater mucus viscosity and secretion retention, which increase the risk of upperairway obstruction. ${ }^{5}$ Although there are no general recommendations or guidelines concerning humidification during NIV, humidifying devices are commonly applied when NIV continues for more than 24 hours, if pipeline or cylinder gas is the inspiratory gas, or if the patient frequently experiences difficulty in expelling secretions or reports dryness and discomfort. ${ }^{6,7}$

A heated humidifier $(\mathrm{HH})$ adds water vapor to the inspiratory gas during NIV. ${ }^{8}$ For patients with obstructive sleep apnea, HH ameliorates nasal congestion and mouth dryness, and improves satisfaction. ${ }^{9,10}$ The humidification performance of $\mathrm{HHs}$, however, varies according to minute ventilation, $\mathrm{F}_{\mathrm{IO}_{2}}$, and gas leak around the interface. ${ }^{11}$ High 
ambient temperature and high temperature of the ventilator output also reduce $\mathrm{HH}$ performance. ${ }^{12}$ Even with $\mathrm{HH}$ some patients with acute respiratory failure (ARF) report oral dryness and discomfort during $\mathrm{NIV}^{13}$ or high-flow oxygen via a oronasal mask. ${ }^{14}$

Although manufacturers recommend that the NIV gas temperature be set at $31^{\circ} \mathrm{C}$ in the $\mathrm{HH}$ chamber and $34^{\circ} \mathrm{C}$ at the Y-piece, ${ }^{15}$ there are few available data on $\mathrm{HH}$ performance or the optimal humidity of the inspired gas during NIV. It has been reported that HH provides an appropriate absolute humidity (AH) (approximately 25$30 \mathrm{mg} \mathrm{H}_{2} \mathrm{O} / \mathrm{L}$ ) and is well tolerated during high-flow CPAP, but those evaluations were performed for only a few hours. ${ }^{15,16}$ Using the recommended settings, our patients often reported discomfort, and we saw no condensation on the inner walls of the oronasal mask. These episodes seemed to be caused by inadequate humidification that caused oral dryness during NIV. There have been no studies on the long-term effects of $\mathrm{HH}$ on hygrometric conditions inside oronasal masks, nor on the relationship between $\mathrm{AH}$ and oral dryness or patient discomfort in patients with ARF.

The purpose of this study was to investigate the longterm effects of $\mathrm{HH}$ on hygrometric properties of inspired gas and oral dryness during NIV. To investigate factors affecting $\mathrm{AH}$ during $\mathrm{HH}$ NIV, we measured $\mathrm{AH}$ inside oronasal masks for 24 hours. We also assessed the oral dryness and discomfort of patients with ARF during NIV.

\section{Methods}

\section{Subjects}

The study was conducted in the ICU of Tokushima University Hospital. Adult patients with ARF who were expected to receive NIV for at least 24 hours were screened for the study. Exclusion criteria were: psychiatric illness or suspected encephalopathy (drug overdose or hepatic failure) that might cause difficulty in scoring the feeling of oral dryness, and severe respiratory or hemodynamic instability that would preclude removal of the NIV mask to evaluate oral dryness. The study protocol was approved by the ethics committee of Tokushima University Hospital (institutional review board number 1034), and written informed consent was obtained from all subjects or their families.

\section{Study Protocol}

NIV was provided with a single-limb turbine ventilator (BiPAP Vision, Respironics, Murrysville, Pennsylvania), an oronasal mask with a swivel exhalation port (ComfortFull 2, Respironics, Murrysville, Pennsylvania), and a humidifier (MR850, Fisher \& Paykel, Auckland, New Zealand) with a heater (MR290, Fisher \& Paykel, Auckland,

\section{QUICK LOOK}

\section{Current knowledge}

Noninvasive ventilation delivers dry medical gas at high flow, which can result in inadequate humidification, oral dryness, and patient discomfort. The optimal humidification settings to avoid untoward events are unknown.

\section{What this paper contributes to our knowledge}

The absolute humidity delivered to an oronasal mask during noninvasive ventilation was impacted by humidifier settings and the amount of leak, and varied among patients at equivalent humidifier settings. The presence of condensate in the mask was associated with improved oral moistness and patient comfort.

New Zealand). The HH was connected to the NIV mask via a standard smooth cylindrical tube with a heater wire. NIV was set on spontaneous/timed mode. The inspiratory positive airway pressure (IPAP), expiratory positive airway pressure (EPAP), $\mathrm{F}_{\mathrm{IO}_{2}}$, breathing frequency, and inspiratory time were adjusted by the attending physicians. The HH was set on NIV mode with compensation algorithm. The temperature setting at the humidification chamber was $31^{\circ} \mathrm{C}$, and at the $\mathrm{Y}$-piece was $34^{\circ} \mathrm{C}$. AH inside the mask was continuously monitored for 24 hours with a capacitive polymer hygrometer (Hygrocron, KN Laboratories, Osaka, Japan). ${ }^{17}$ This hygrometer has a stainless steel housing and a hydrophobic filter to protect against environmental hazards such as dirt, condensation, and impact. In an operating range for relative humidity (RH) of $0-100 \%$, measurements were taken every minute. The response time of this hygrometer is 30 seconds in the $\mathrm{RH}$ range $40-90 \%$ at $25^{\circ} \mathrm{C}$ and flow of $5 \mathrm{~L} / \mathrm{min}$.

After commencement of AH monitoring, when the subject's respiratory status was stable, oral moistness was measured at the surface of the buccal mucosa, $10 \mathrm{~mm}$ behind the labial angle, with an oral hygrometer (Moisture Checker for Mucus, Scalar, Tokyo, Japan $)^{18}$ that measures percent weight of water in the oral mucosal epithelium with the capacitance from the dielectric constant. Water content and the dielectric constant are positively correlated, and as the dielectric constant of water is markedly higher than that of other substances, the percentage of water in the substance can be determined by measuring the dielectric constant of the substance. The usefulness and ease of use of this oral hygrometer (within 2 seconds) have been reported. ${ }^{19,20}$

Following the manufacturer's definitions, oral moistness over $29 \%$ was considered normal, 25-29\% was considered dry, and $<25 \%$ was considered severely dry. Each 
Table 1. Subjects

\begin{tabular}{|c|c|}
\hline Male/female, no. & $9 / 7$ \\
\hline Age, y & $75(61-77)$ \\
\hline Body mass index, $\mathrm{kg} / \mathrm{m}^{2}$ & $24.1(22.5-27.1)$ \\
\hline APACHE II score & $21(18-29)$ \\
\hline Duration of NIV, $\mathrm{h}$ & $75(62-132)$ \\
\hline Time from NIV start to study, $\mathrm{h}$ & $28(13-42)$ \\
\hline \multicolumn{2}{|l|}{ Reason for NIV, no. (\%) } \\
\hline Congestive heart failure & $5(31)$ \\
\hline Pneumonia & $4(25)$ \\
\hline Postoperative respiratory failure & $3(19)$ \\
\hline Sepsis & $2(13)$ \\
\hline Other & $2(13)$ \\
\hline Body temperature, ${ }^{\circ} \mathrm{C}$ & $37.1(36.6-37.4)$ \\
\hline $\mathrm{P}_{\mathrm{aO}_{2}} / \mathrm{F}_{\mathrm{IO}_{2}}, \mathrm{~mm} \mathrm{Hg}$ & $222(150-270)$ \\
\hline $\mathrm{P}_{\mathrm{aCO}_{2}}, \mathrm{~mm} \mathrm{Hg}$ & $39(31-46)$ \\
\hline $\mathrm{pH}$ & $7.48(7.44-7.50)$ \\
\hline \multicolumn{2}{|c|}{$\begin{array}{l}\text { Values are median (IQR) unless otherwise indicated. } \\
\text { APACHE = Acute Physiology and Chronic Health Evaluation } \\
\text { NIV = noninvasive ventilation }\end{array}$} \\
\hline
\end{tabular}

measurement was performed in triplicate, and the median values were used in the subsequent analysis. At the same time as the oral hygrometry, we asked the subjects to rate their feeling of oral dryness at that point in time, on a 1-10 scale in which 0 is normal and 10 is the most severe dryness. Oral dryness scores of 1-3 were defined as mild, 4-6 as moderate, and 7-10 as severe. Oral hygrometry and subjective oral dryness scoring were recorded at the beginning, middle, and the end of the study period, with intervals of 8-12 hours, as were the NIV settings, including IPAP/EPAP, $\mathrm{F}_{\mathrm{IO}_{2}}$, inspired gas leak, minute ventilation, breathing frequency, presence of oral breathing, and level of condensation on the inside wall of the oronasal mask. Oral breathing was defined as breathing with the mouth open during both inhalation and exhalation. The condensation level on the inside walls of the mask was assessed via visual inspection and rated as follows: $1=$ no condensation visible on mask walls, 2 = patches of nondroplet condensation, 3 = non-droplet condensation over entire mask wall, $4=$ some droplets, $5=$ numerous droplets.

\section{Statistical Analysis}

Normally distributed data are presented as mean \pm SD. Non-normally distributed data are presented as median and IQR. The Mann-Whitney $U$ test was used to evaluate non-paired measurements. Analysis of variance was performed with the Friedman test, with Bonferroni correction. To determine the factors associated with $\mathrm{AH}$, oral moistness, and oral dryness score, we used the correlation co-
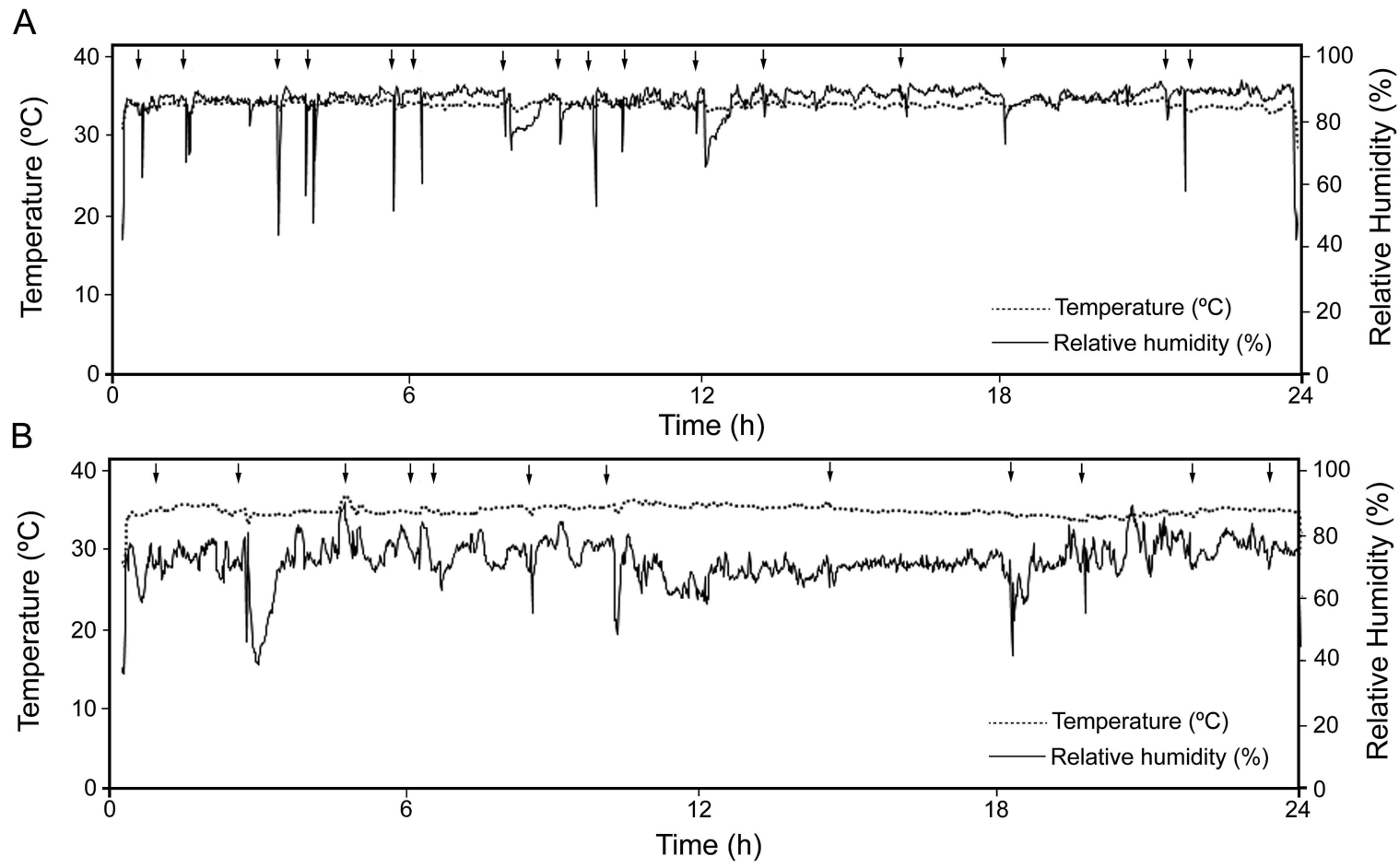

Fig. 1. Typical examples of hygrometry curves during noninvasive ventilation. In subject 1 (A) the relative humidity range is $85-90 \%$ and the temperature range is $32-35^{\circ} \mathrm{C}$, except when the mask was removed for dryness measurements (arrows). In subject 2 (B) the relative humidity was $<80 \%$, despite that the temperature was maintained at $32-35^{\circ} \mathrm{C}$. 


\section{Hygrometric Properties of Inspired Gas and Oral Dryness}

efficients of variance within subjects, and analysis of covariance and the correlation coefficients of variance between subjects, using the mean for repeated observations. Both correlation coefficients were calculated according to the methods of Bland and Altman. ${ }^{21,22}$ The relationship between $\mathrm{AH}$ and condensation was determined with the correlation coefficient, using the mean for repeated observations. The effects of oral breathing on oral moistness and dryness were analyzed with the unpaired $t$ test, using a mean for repeated observations. Oral dryness score and condensation score were treated as continuous data. To evaluate the relationship between $\mathrm{AH}$, which was measured every minute, and other variables, which were measured every 8-12 hours, we used the AH values recorded immediately before the other measurements. Statistical analysis was performed with statistics software (PASW Statistics 18, SPSS, Chicago, Illinois). All statistical tests were 2 -sided, and a $P$ value $<.05$ was considered statistically significant.

\section{Results}

We enrolled 16 subjects: 9 male and 7 female. Six subjects required intubation after NIV, and 2 died during ICU admission. All the other subjects were successfully weaned from NIV. Table 1 summarizes the subject data for age, sex, reason for NIV, Acute Physiology and Chronic Health Evaluation II scores, duration of NIV, duration of NIV prior to the study, and respiratory status.

\section{Hygrometric Conditions Within the Mask}

At the beginning of the study the ambient air temperature range was $24.3-28.2^{\circ} \mathrm{C}$ (median $27.6^{\circ} \mathrm{C}$ ), the RH range was $18.2-61.1 \%$ (median $41.3 \%$ ), and the $\mathrm{AH}$ range was $4.0-14.7 \mathrm{mg} \mathrm{H}_{2} \mathrm{O} / \mathrm{L}$ (median $10.7 \mathrm{mg}$ $\mathrm{H}_{2} \mathrm{O} / \mathrm{L}$ ). Inside the mask the mean $\pm \mathrm{SD}$ values were: AH $30.0 \pm 2.6 \mathrm{mg} \mathrm{H}_{2} \mathrm{O} / \mathrm{L}$ (range 23.1-33.3 $\mathrm{mg} \mathrm{H}_{2} \mathrm{O} / \mathrm{L}$ ), RH $79.4 \pm 6.9 \%$ (range 62.4-89.3\%), temperature $33.9 \pm 0.6^{\circ} \mathrm{C}$ (range $32.9-34.9^{\circ} \mathrm{C}$ ). Figure $1 \mathrm{~A}$ shows a typical time course for $\mathrm{RH}$ and temperature inside the mask. Except when the mask was removed for nursing care or assessing dryness, $\mathrm{RH}$ was maintained at $85-90 \%$ and temperature at $32-35^{\circ} \mathrm{C}$. However, in some subjects $\mathrm{RH}$ was lower, despite the temperature being maintained at $32-35^{\circ} \mathrm{C}$ (see Fig. 1B). AH and gas leak correlated inversely within the subjects $(\mathrm{r}=-0.56, P<.001)$ and between the subjects $(\mathrm{r}=-0.58, P=.02)$ (Fig. 2). AH was not associated with minute ventilation, breathing frequency, IPAP, EPAP, or $\mathrm{F}_{\mathrm{IO}_{2}}$ (data not shown). Visual scoring of condensation inside the mask and $\mathrm{AH}$ closely correlated between the subjects $(\mathrm{r}=0.82, P<.001)$ (Fig. 3 ).

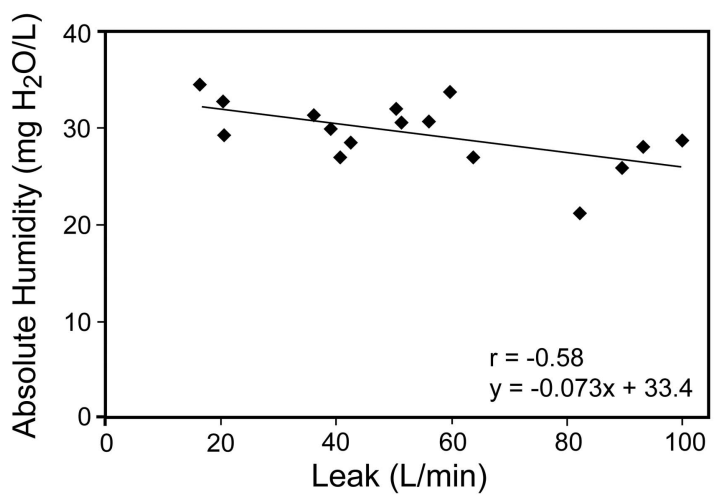

Fig. 2. Relationship between absolute humidity and air leak between the subjects. Absolute humidity and gas leak inversely correlated between the subjects.

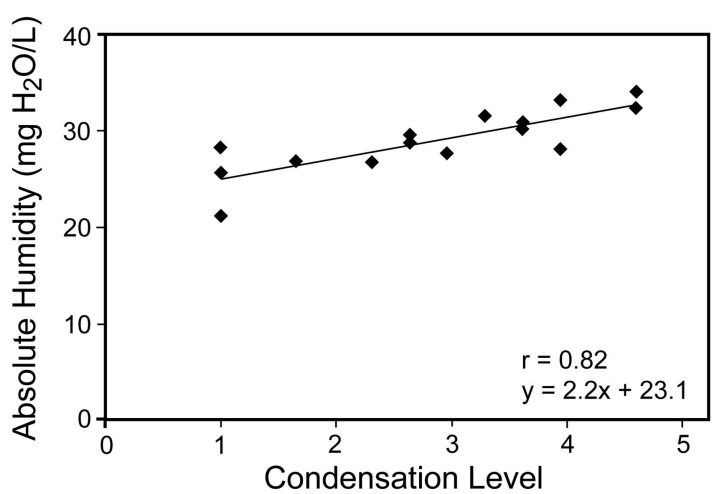

Fig. 3. Relationship between absolute humidity and visual rating of condensation on the inner walls of the oronasal mask between the subjects. Condensation score and absolute humidity closely correlated between the subjects.

\section{Oral Hygrometry Measurements and Subjective Oral Dryness Scores}

Two subjects had multiple oral-mucosa ulcers, and no oral hygrometry measurements were taken from those 2 subjects. Oral hygrometry data were collected at 42 time points. Subjective oral dryness was scored by all 16 subjects, at 48 time points. The median value for objectively measured oral moistness was $19.2 \%$ (IQR 4.4-24\%), and that for subjective oral dryness score was 5.5 (IQR 4-7). Oral moistness and subjective oral dryness remained the same throughout the study period (Table 2). Twelve of 14 subjects had severe dryness (oral moistness $<25 \%$ ), and 8 of 16 subjects reported feeling severe oral dryness (oral dryness score 7-10) at least once. AH and oral moistness correlated within the subjects $(\mathrm{r}=0.39, P=.04)$, but not between the subjects $(\mathrm{r}=0.45, P=.11)$. The relationship between $\mathrm{AH}$ and oral dryness was not significant within the subjects $(\mathrm{r}=-0.26, P=.14)$ or between the subjects $(\mathrm{r}=-0.35, P=.19)$. For subjects with oral breathing, 
Table 2. Oral Hygrometry Values, Subjective Oral Dryness Score, Noninvasive Ventilation Settings, and Respiratory Status

\begin{tabular}{|c|c|c|c|c|}
\hline & \multicolumn{3}{|c|}{ Time Point in the 24-Hour Study Period } & \multirow[b]{2}{*}{$P \dagger$} \\
\hline & Beginning & Intermediate & End & \\
\hline Oral hygrometry measurement, $\% *$ & $16.0(4.2-24.9)$ & $18.5(4.6-23.6)$ & $22.0(10.7-23.4)$ & .86 \\
\hline Subjective oral dryness score & $5.5(4.0-7.3)$ & $6.5(4.5-7.3)$ & $5.0(4.0-7.0)$ & .98 \\
\hline \multicolumn{5}{|l|}{ Noninvasive ventilation settings } \\
\hline Inspiratory pressure, $\mathrm{cm} \mathrm{H}_{2} \mathrm{O}$ & $8(8-9)$ & $8(8-9)$ & $8(8-8)$ & .72 \\
\hline Expiratory pressure, $\mathrm{cm} \mathrm{H}_{2} \mathrm{O}$ & $7(6-8)$ & $8(6-8)$ & $8(6-8)$ & .36 \\
\hline $\mathrm{F}_{\mathrm{IO}_{2}}$ & $0.5(0.5-0.5)$ & $0.5(0.4-0.5)$ & $0.5(0.4-0.5)$ & .62 \\
\hline Minute volume, $\mathrm{L} / \mathrm{min}$ & $9.5(7.5-11.0)$ & $9.0(7.8-10.3)$ & $8.0(6.8-10.0)$ & .51 \\
\hline Breathing frequency, breaths/min & $21(20-29)$ & $21(18-26)$ & $20(18-24)$ & .18 \\
\hline Leak, L/min & $41(28-70)$ & $58(37-79)$ & $47(34-82)$ & .75 \\
\hline Oral breathing, no. $(\%)$ & $6(38)$ & $6(38)$ & $5(31)$ & $>.99$ \\
\hline \multicolumn{5}{|l|}{$\begin{array}{l}\text { Values are median (IQR) unless otherwise indicated. } \\
\text { * Data were collected from } 14 \text { of the } 16 \text { subjects. } \\
\dagger \text { Via Friedman test with Bonferroni correction. }\end{array}$} \\
\hline
\end{tabular}
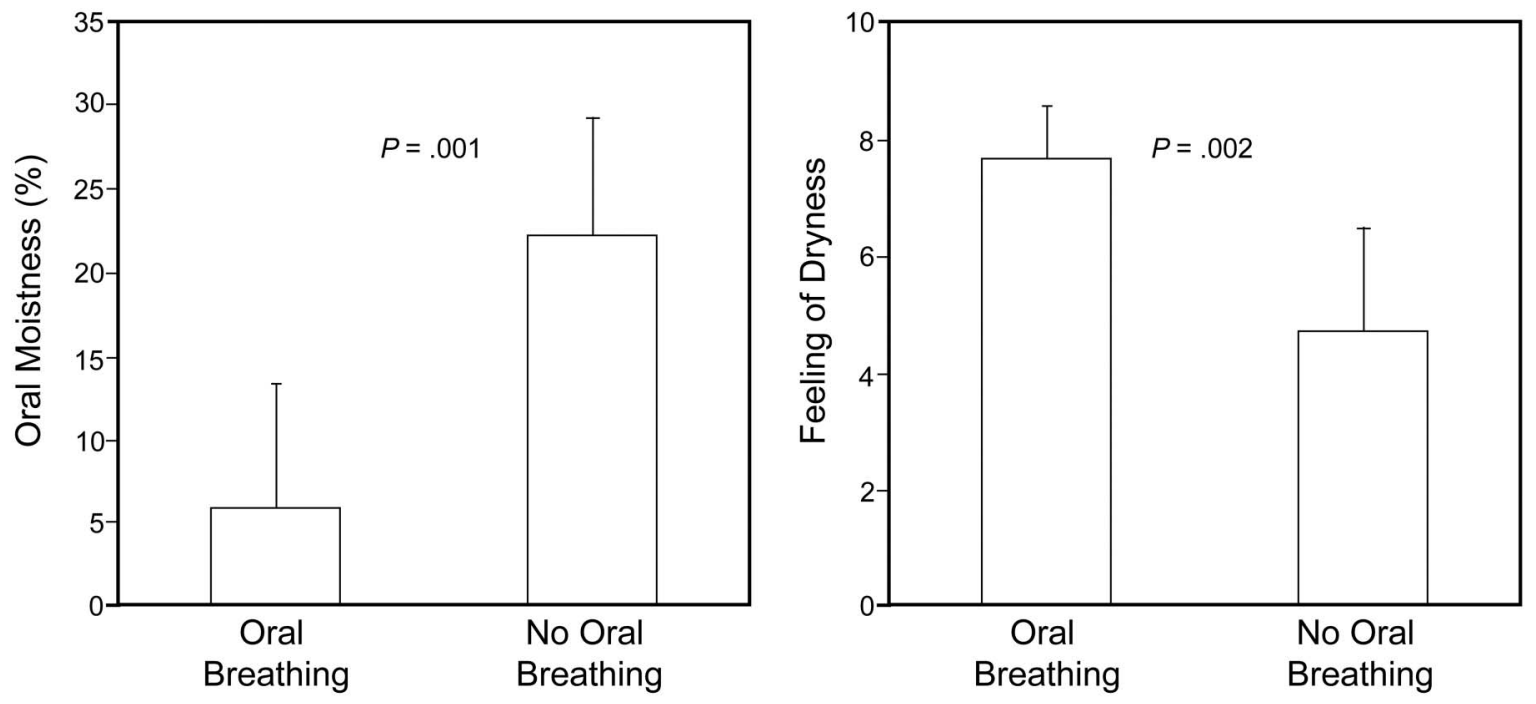

Fig. 4. Effect of oral breathing on oral moistness and feeling of oral dryness. The subjects with oral breathing had lower oral moistness than the subjects without oral breathing. The subjects with oral breathing reported significantly worse oral dryness than the subjects without oral breathing. The data bars represent the mean values, and the whisker bars represent the standard deviations.

oral moistness was significantly lower $(P=.001)$ and oral dryness score significantly higher $(P=.002)$ than for the subjects without oral breathing (Fig. 4). There were no significant differences in $\mathrm{AH}$ between the subjects with and without oral breathing $\left(28.5 \pm 2.6 \mathrm{mg} \mathrm{H} \mathrm{H}_{2} \mathrm{O} / \mathrm{L}\right.$ with oral breathing vs $29.9 \pm 3.8 \mathrm{mg} \mathrm{H}_{2} \mathrm{O} / \mathrm{L}$ without oral breathing, $P=.46)$. Neither the values for oral moistness nor for oral dryness score correlated with minute ventilation, breathing frequency, IPAP, EPAP, or $\mathrm{F}_{\mathrm{IO}_{2}}$ (data not shown).

\section{Discussion}

This study is the first to continuously evaluate hygrometric conditions inside the oronasal mask during 24 hours of NIV. We found that even with the same HH settings, AH varied among the subjects. As inspiratory gas leak increased, AH decreased. AH inside the mask correlated with oral moistness within the subjects. Oral breathing decreased oral moistness and worsened the feeling of dryness. Visual evaluation of condensation on the inside walls of the mask correlated with $\mathrm{AH}$.

We evaluated the hygrometric conditions inside the masks used for administering gas conditioned by servocontrolled HH in NIV mode, with temperature set in the humidification chamber at $31^{\circ} \mathrm{C}$ and in the Y-piece at $34^{\circ} \mathrm{C}$. When gas in the chamber is fully saturated with vapor, $\mathrm{AH}$ should be $32.2 \mathrm{mg} \mathrm{H}_{2} \mathrm{O} / \mathrm{L}$, and $\mathrm{RH}$ should 


\section{Hygrometric Properties of Inspired Gas and Oral Dryness}

be $85 \%$ at the $\mathrm{Y}$-piece (at $31^{\circ} \mathrm{C}$ with $100 \% \mathrm{RH}=$ $32.2 \mathrm{mg} \mathrm{H}_{2} \mathrm{O} / \mathrm{L}$, at $34^{\circ} \mathrm{C}$ with $100 \% \mathrm{RH}=37.9 \mathrm{mg} \mathrm{H}_{2} \mathrm{O} /$ $\mathrm{L})$. Although the temperature inside the mask was $33.9^{\circ} \mathrm{C}$,

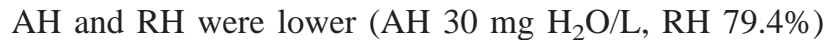
than the theoretical values. Humidity inside the mask depends on both the amount of vapor in the expired gas and the amount in the gas delivered into the mask. During spontaneous breathing, air drawn into the body is heated to $37^{\circ} \mathrm{C}$ and fully humidified by evaporation of water from the airway mucosa. ${ }^{4,23}$ The high internal gas volume of the mask should facilitate transfer of expired heat and humidity to fresh incoming gas. ${ }^{24,25}$ One possible reason why servo-controlled $\mathrm{HH}$ provided lower-than-expected $\mathrm{AH}$ and $\mathrm{RH}$ is gas leak: the amount of leak inversely correlated with AH. Leak from the mask during NIV increases the gas flow delivered by the NIV ventilator, which operates to maintain the set level of positive pressure and so supplies an increased proportion of dry fresh gas for mixing with the expired gas. ${ }^{2,4}$

In the present study, $\mathrm{AH}$ correlated with oral moistness within the subjects, but not between the subjects. Although we maintained higher $\mathrm{AH}$ than in previous reports, $50 \%$ of the subjects complained at least once during the study of severe dryness (oral dryness score $\geq 7$ ). These results indicate that a high $\mathrm{AH}$ improves oral moistness to some extent, but does not always maintain the appropriate oral moistness or eliminate the feeling of oral dryness. Little has been published about the optimal humidification during NIV. It has been reported that ambient $\mathrm{AH}$ (below $10 \mathrm{mg} \mathrm{H}_{2} \mathrm{O} / \mathrm{L}$ ) is associated with upper airway dryness that, with the application of humidification, could be reduced during nasal CPAP for obstructive sleep apnea. ${ }^{3,4,25}$ In healthy volunteers, while there was no difference in tolerance of $\mathrm{AH}$ of $15 \mathrm{mg} \mathrm{H}_{2} \mathrm{O} / \mathrm{L}$ versus $30 \mathrm{mg} \mathrm{H}_{2} \mathrm{O} / \mathrm{L}$ during high-flow CPAP, dry gas $\left(5 \mathrm{mg} \mathrm{H}_{2} \mathrm{O} / \mathrm{L}\right)$ was less well tolerated than humidified gas. ${ }^{14}$

We enrolled patients with ARF, the majority of whom received NIV for more than 24 hours prior to the study. The causes of oral dryness in subjects with ARF are multifactorial and include high minute ventilation, oral breathing, withholding oral intake, and dehydration. ${ }^{26}$ Whereas in previous studies $\mathrm{AH}$ was measured in the tube system, which is not affected by expired gas, we measured $\mathrm{AH}$ inside the mask: the intermingling of the delivered and expired gas inside the mask resulted in higher $\mathrm{AH}$ than in previous studies. ${ }^{15,23}$ Oral breathing decreased oral moistness and worsened the feeling of dryness, even though $\mathrm{AH}$ did not differ between the subjects with and without oral breathing. It is generally understood that oral breathing frequently causes oral dryness, owing to fluid loss by evaporation. $^{27}$ In particular, the high flow of dry, cold gas contributes to the evaporation of oral mucosal fluid. To prevent oral dryness and discomfort during NIV, integrated strategies may be needed for orally breathing patients.
The visual evaluation of condensation was closely associated with $\mathrm{AH}$ inside the mask. In clinical practice, hygrometric measurements are not taken during NIV, and physicians remain uncertain how best to ensure that humidification is adequate. During invasive ventilation, visual inspection of the condensation in the circuit is a good means of judging the adequacy of humidification. ${ }^{12}$ Heated inspiratory gas, however, is cooled as it passes, without further heating, through the tube or mask, resulting in condensation during NIV. ${ }^{28}$ Our results suggest that condensation inside the mask may be a useful clinical marker for determining whether humidification is adequate during NIV.

\section{Limitations}

We evaluated only one $\mathrm{HH}$ setting, so we could not address the question of how much humidification is needed to prevent oral dryness. To evaluate the $\mathrm{AH}$ that would prevent oral dryness, it will be necessary to measure $\mathrm{AH}$ with various humidification settings, including without $\mathrm{HH}$ and with the $\mathrm{HH}$ set to a higher temperature.

We used a single-limb turbine ventilator and a mask that has continuous leak through the exhalation port. Part of the gas came from the ambient air, through a compressor. In addition, we used a moderate $\mathrm{F}_{\mathrm{IO}_{2}}(0.4-0.5)$. Our results should be different from NIV studies that used ICU ventilators and cold, dry gas (which would decrease $\mathrm{AH}$ ) and masks with minimal leak (which would limit the $\mathrm{AH}$ decrease). Different ventilators, different masks, or higher $\mathrm{F}_{\mathrm{IO}_{2}}$ might produce different results.

The response time of the humidity sensor we used was 30 seconds, so this hygrometer was unable to respond quickly enough to detect the minimum inspiratory humidity during the respiratory cycle time. This hygrometer may have detected the nearly average humidity values inside the mask. However, because we investigated the effects of $\mathrm{HH}$ inside the mask for 24 hours, it was reasonable to measure the humidity average inside the mask for our primary purpose.

\section{Conclusions}

Even when the same $\mathrm{HH}$ settings are applied, $\mathrm{AH}$ varied among our subjects. Inspiratory gas leak affected the humidification performance of the $\mathrm{HH}$, and $\mathrm{AH}$ correlated with oral moistness within the subjects and with the visually assessed condensation scores. Oral breathing decreased oral moistness and worsened the feeling of dryness. Clinicians should ensure that proper humidification is supplied when patients complain of oral dryness or when little condensation is observed inside the mask. 


\section{Hygrometric Properties of Inspired Gas and Oral Dryness}

\section{REFERENCES}

1. Hess DR. The evidence of noninvasive positive pressure ventilation in the case of patients in acute respiratory failure. Respir Care 2004; 49(7):810-829.

2. Branson RD, Gentile MA. Is humidification always necessary during noninvasive ventilation in the hospital? Respir Care 2010;55(2): 209-216.

3. Mador MJ, Krauza M, Pervez A, Pierce D, Braun M. Effect of heated humidification on compliance and quality of life in patients with sleep apnea using nasal continuous positive airway pressure. Chest 2005;128(4):2151-2158.

4. Pépin JL, Leger P, Veale D, Langevin B, Robert D, Lévy P. Side effects of nasal continuous positive airway pressure in sleep apnea syndrome. Study of 193 patients in two French sleep centers. Chest 1995;107(2):375-381.

5. Wood KE, Flaten AL, Backes WJ. Inspissated secretions: a lifethreatening complication of prolonged noninvasive ventilation. Respir Care 2000;45(5):491-493.

6. Mehta S, Hill NS. Noninvasive ventilation. Am J Respir Crit Care Med 2001;163(2):540-577.

7. Evans TW. International consensus conference in intensive care medicine: non-invasive positive pressure ventilation in acute respiratory failure. Organized jointly by the American Thoracic Society; European Respiratory Society; European Society of Intensive Care Medicine; Société de Réanimation de Langue Française; approved by the ATS Board of Directors, December 2000. Intensive Care Med 2001; 27(1):166-178.

8. Nava S, Navalesi P, Gregoretti C. Interfaces and humidification for noninvasive mechanical ventilation. Respir Care 2009;54(1):71-84.

9. Martins de Araújo MT, Vieira SB, Vasquez EC, Fleury B. Heated humidification or face mask to prevent upper airway dryness during continuous positive airway pressure therapy. Chest 2000;117(1): 142-147.

10. Wiest GH, Lehnert G, Brûck WM, Meyer M, Hahn EG, Ficker JH. A heated humidifier reduces upper airway dryness during continuous positive airway pressure therapy. Respir Med 1999;93(1):21-26.

11. Nishida T, Nishimura M, Fujino Y, Mashimo T. Performance of heated humidifiers with a heated wire according to ventilatory settings. J Aerosol Med 2001;14(1):43-51.

12. Lellouche F, Taillé S, Maggiore SM, Qader S, L'Her E, Deye N, Brochard L. Influence of ambient and ventilator output temperatures on performance of heated-wire humidifiers. Am J Respir Crit Care Med 2004;170(10):1073-1079.

13. Oto J, Imanaka H, Nishimura M. Clinical factors affecting inspired gas humidification and oral dryness during noninvasive ventilation. J Crit Care 2011;26(5):535.e9-e15.

14. Chanques G, Constantin JM, Sauter M, Jung B, Sebbane M, Verzilli $\mathrm{D}$, et al. Discomfort associated with underhumidified high-flow oxygen therapy in critically ill patients. Intensive Care Med 2009; 35(6):996-1003.

15. Lellouche F, Maggiore SM, Lyazidi A, Deye N, Taillé S, Brochard L. Water content of delivered gases during non-invasive ventilation in healthy subjects. Intensive Care Med 2009;35(6):987-995.

16. Chiumello D, Chierichetti M, Tallarini F, Cozzi P, Cressoni M, Polli $\mathrm{F}$, et al. Effect of a heated humidifier during continuous positive airway pressure delivered by a helmet. Crit Care 2008;12(2):R55.

17. Davis RR, Shaw PB. Heat and humidity buildup under earmuff-type hearing protectors. Noise Health 2011;13(51):93-98.

18. Yamada H, Nakagawa Y, Nomura Y, Yamamoto K, Suzuki M, Watanabe NY, et al. Preliminary results of moisture checker for mucus in diagnosing dry mouth. Oral Dis 2005;11(6):405-407.

19. Takahashi F, Takahashi M, Toya S, Koji T, Morita O. Clinical usefulness of an oral moisture checking device (mucus). Prosthodont Res Pract 2006;5:214-218.

20. Murakami M, Nishi Y, Kamashita Y, Nagaoka E. Relationship between medical treatment and oral dryness diagnosed by oral moisture-checking device in patients with maxillofacial prostheses. J Prosthodont Res 2009;53(2):67-71.

21. Bland JM, Altman DG. Calculating correlation coefficients with repeated observations: part 1: correlation within subjects. BMJ 1995; 310(6977):446.

22. Bland JM, Altman DG. Calculating correlation coefficients with repeated observations: part 2: correlation between subjects. BMJ 1995; 310(6980):633.

23. Williams R, Rankin N, Smith T, Galler D, Seakins P. Relationship between the humidity and temperature of inspired gas and the function of the airway mucosa. Crit Care Med 1996;24(11):1920-1929.

24. Schettino GP, Chatmongkolchart S, Hess DR, Kacmarek RM. Position of exhalation port and mask design affect $\mathrm{CO}_{2}$ rebreathing during noninvasive positive pressure ventilation. Crit Care Med 2003; 31(8):2178-2182.

25. Wiest GH, Foerst J, Fuchs FS, Schmelzer AH, Hahn EG, Ficker JH. In vivo efficacy of two heated humidifiers used during CPAPtherapy for obstructive sleep apnea under various environmental conditions. Sleep 2001;24(4):435-440.

26. Primiano FP Jr, Montague FW Jr, Saidel GM. Measurement system for respiratory water vapor and temperature dynamics. J Appl Physiol 1984;56(6):1679-1685.

27. Verma M, Seto-Poon M, Wheatley JR, Amis TC, Kirkness JP. Influence of breathing route on upper airway lining liquid surface tension in humans. J Physiol 2006;574(Pt 3):859-866.

28. Bacon JP, Farney RJ, Jensen RL, Walker JM, Cloward TV. Nasal continuous positive airway pressure devices do not maintain the set pressure dynamically when tested under simulated clinical conditions. Chest 2000;118(5):1441-1449.

This article is approved for Continuing Respiratory Care Education credit. For information and to obtain your CRCE

(free to AARC members) visit

www.rcjournal.com

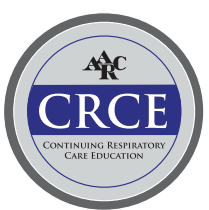

